\title{
Fracking, worksite injuries, and Aeromonas infection
}

\author{
Larrite Reed BS, Johnathan Umelo BS, Shirley Cotty BS
}

\begin{abstract}
Hydraulic fracturing or fracking is a method of extracting natural gas from the earth using high pressure drilling equipment and fracking fluid that contains proppant and various chemicals. It poses health risks to workers at the drilling sites, has effects on water and air quality, and creates potential health risks for people living near the drilling sites. A 30-yearold man with no past medical history presented as transfer from an outside hospital after an explosion on a fracking job site. This explosion released over 6000 pounds of water that threw him 20 feet across the rig. He had radial and ulnar fractures in his right arm and digital fractures on his right hand. He also had trauma to his left knee and right posterior thigh with a large fluctuant Morel-Lavallee lesion. On day 3 the patient developed hypotension, lethargy, and new onset fever from a possible infection of a hematoma; he was started on norepinephrine and intubated due to a decreased mental status. Cultures from the thigh were positive for Aeromonas species. Aeromonas is a Gram-negative rod that is found in many environments that contain water. Studies have shown that this organism grows commonly in West Texas and New Mexico in river beds and lakes. Healthcare providers should keep Aeromonas spp in their differential list of pathogens in patients with abrasions and open injuries that occurred around or in a body of water.
\end{abstract}

Keywords: fracking, work site trauma, abscess, Aeromonas species

\section{INTRODUCTION}

Fracking for oil and gas is a huge market attracting new workers due to the pay and sheer number of available jobs. The Eagle Ford shale, which contains about $13 \%$ of all natural gas in the United States, will create approximately 117,000 new jobs and over 90 billion dollars by the end of 2021. ${ }^{1}$ Jobs in the fracking industry often involve handling of hazardous waste.

Hydraulic fracturing or fracking is a method of extracting natural gas from the earth using high

Corresponding author: Larrite Reed

Contact Information: Larrite.reed@ttuhsc.edu

DOI: 10.12746/swrccc.v7i28.544 pressure drilling equipment and fracking fluid that contains proppant and various chemicals; ${ }^{2}$ it poses health risks to workers at the drilling sites, has effects on water and air quality, and creates potential health hazards for people living near the drilling sites. The workers at the drilling site can be exposed to various risks, including falls, injuries by tools or falling objects at the site, and injuries related to heavy equipment or unguarded machinery. ${ }^{3}$ The oil and gas industry is well known for its inherently hazardous working environment. The Center of Disease Control and Prevention (CDC) stated that there was a $15 \%$ increase in fatalities from 2003 to 2006 among workers in this industry in the United States. The fatalities involved vehicles (110), being struck by objects (88), explosions on site (36), falls (30), fires (27), and being caught in machinery (26). These figures, according to the CDC, represent increased fatalities just before the surge in 
hydraulic fracturing. The CDC also reported that there is a direct correlation between production levels of oil and gas and increased fatalities. ${ }^{4}$

A case series in 2016 detailed how eight workers sustained traumatic injuries over a 14-month period. They were mostly men (88\%) with an average age of 33.5 years. The most common method of injury was explosion, which resulted in burns and muscle, abdominal, or soft tissue injuries. Seventy-five percent of these patients sustained cutaneous injuries that were mostly caused by fires, chemicals, and scalding. Most of these patients required surgery and on average stayed in the hospital and intensive care units for 26.4 and 17.6 days, respectively. ${ }^{1}$

\section{CASE}

A 30-year-old man with no past medical history presented as transfer from an outside hospital complaining of right arm and left knee pain after an explosion on a fracking job site. The explosion released over 6000 pounds of water that threw him 20 feet across the rig. The patient stated that he remembers only waking up in his local hospital. He was subsequently transferred to our hospital for orthopedic hand surgery. One fatality occurred on the scene during this accident.

His physical examination was within normal limits except for open fractures to the 1st and 2nd metatarsals and lacerations and tenderness around the medial aspect of left knee. Relevant laboratory tests during this hospitalization included WBC $17.2 \mathrm{~K} / \mu \mathrm{L}$ (peak level), hemoglobin $6.1 \mathrm{gm} / \mathrm{dL}$ (nadir), glucose $142 \mathrm{mg} / \mathrm{dL}$ (peak level), CK 3185 IU/L (peak level), myoglobin $1140 \mathrm{ng} / \mathrm{mL}$ (peak level), and AST $203 \mathrm{IU} / \mathrm{L}$ (peak level).

The patient was admitted to the orthopedic service, which diagnosed radial and ulnar fractures that required an open reduction and internal fixation. He also had fixation of fractures in his right hand. An MRI of the left knee showed a partial thickness posterior cruciate ligament tear, a distal medial cruciate ligament tear, and a possible medial meniscal posterior root radial tear. He also had a large fluctuant MorelLavallee lesion in the right posterior thigh which would require surgical management. While in the operating room (OR), he had a washout of the hand, his upper extremity was splinted, and his knee was placed in an immobilizer. The patient also had a $5 \mathrm{~cm}$ posterior scalp lesion that was repaired with six staples after surgery.

On hospital day 3 the patient developed hypotension, lethargy, and new onset fever from a possible infection of a hematoma. He was started on IV fluids and broad spectrum antibiotics and scheduled for an incision and drainage of the right posterior thigh wound. Later that evening the patient decompensated and was started on norepinephrine and intubated due to a decreased mental status. His blood pressure improved enough to go to the OR for incision and drainage. The culture from his thigh was positive for Aeromonas species which was pan sensitive to multiple antibiotics, and he was treated with piperacillintazobactam. The patient required six surgical procedures on his right arm, hand, and leg during his initial hospitalization and four additional procedures during two subsequent hospitalizations.

\section{Discussion}

Aeromonas is a Gram-negative rod found in many environments that contain water; it grows commonly West Texas and New Mexico in river beds and lakes. ${ }^{5-7}$ Aeromonas is typically associated with gastroenteritis, but when cultured from an infected wound, it is usually associated with previous surgery or aquaticrelated trauma. ${ }^{6-8}$ Quinolones and second-and thirdgeneration cephalosporins are generally considered the most effective antimicrobial agents against aeromonads in current clinical settings ${ }^{6,8}$ Aminoglycosides, fluoroquinolones, carbapenems, aztreonam, and third generation cephalosporins are usually active against A. veronii. Penicillin, ampicillin, cefazolin, ticarcillin, and streptomycin are not recommended, since Aeromonas species are frequent beta lactamase producers. Also there have been studies that show Aeromonas can transfer resistance genes to certain antibiotics. ${ }^{5,6}$ The combination of early antibiotic treatment along with surgical debridement when needed can prevent progression to bacteremia, myonecrosis, and organ failure. Aeromonas hydrophila has been reported to have 
a mortality rate of $60-70 \%$ once it invades the muscle and of $80 \%$ once necrotizing fasciitis is diagnosed. ${ }^{8}$ The effects of infection in immunocompromised patients is even greater. A study that closely followed two immunocompromised patients reported the aggressive nature of these bacterial infections with the patients developing septic shock, rhabdomyolysis, and myonecrosis; one patient died within 48 hours of diagnosis. ${ }^{9}$

In our patient his infection with the Aeromonas spp caused a prolonged and complicated hospital course stay. During the evaluation of patients in emergency departments who have abrasions and open injuries that occurred in association with water, such as our patient on a fracking rig, it is important for healthcare providers to keep Aeromonas spp in their differential list of pathogens. Since this microbe can cause severe infection and transmits resistance genes, early antibiotic treatment with broad coverage and cultures of the wound are essential.

Article citation: Reed L, Umelo J, Cotty S. Fracking, worksite injuries, and Aeromonas infection. The Southwest Respiratory and Critical Chronicles 2019;7(28):44-46

From: The Department of Internal Medicine at Texas Tech University Health Sciences Center in Lubbock, Texas

Submitted: $1 / 13 / 2019$

Accepted: 4/8/2019

Reviewer: David Sotello

Conflicts of interest: none

This work is licensed under a Creative Commons Attribution-ShareAlike 4.0 International License.

\section{REFERENCES}

1. Williams J F, Lundy JB, Chung KK, et al. Traumatic injuries incidental to hydraulic well fracturing: a case series. $J$ Burn Care Res 2016;37(2):e188-92.

2. McCurdy R. High rate hydraulic fracturing additives in nonMarcellus unconventional shales. In: Hydraulic Fracturing Technical Presentation Session 1: Fracture Fluid Formulations and Purposes. Presented at U.S. EPA Proceedings of the Technical Workshops for the Hydraulic Fracturing Study: Chemical \& Analytical Methods, Arlington, Virginia, September 28, 2017, p. 1-30.

3. Laborers' Health and Safety Fund of North America. Scott Schneider. Occupational Safety and Health Risks of Fracking Operations. Published: October, 2013; Vol 10, Num 5. Available at: https://www.lhsfna.org/index.cfm/lifelines/october-2013/occupational-safety-and-health-risks-of-fracking-operations/ [Accessed 2 Sep. 2018].

4. Centers for Disease Control. Fatalities among oil and gas extraction workers-United States, 2003-2006. Morbidity Mortality Wkly Rep 2008;57:429-31.

5. Huddleston JR, Zak JC, Jeter RM. Antimicrobial susceptibilities of Aeromonas spp. isolated from environmental sources. Appl Environ Microbiol 2006;72(11):7036-42.

6. Kimbrough RC, Winn RE, Jeter RM, et al. Aeromonas infection from river and playa lake waters in West Texas and southeastern New Mexico. The Southwest Respiratory and Critical Care Chronicles 2016;4(16):19-25.

7. McKenzie P, Sotello D, Hailemariam Y, et al. Aeromonas veronii septicemia in an immunocompetent patient. The Southwest Respiratory and Critical Care Chronicles 2013;1(4)50-52.

8. Koschel S, Manning T, Perera M, et al. Successful split thickness skin grafting in the presence of heavy colonization with rare bacterium Aeromonas hydrophila: a case report. JPRAS Open 2017;13:20-23.

9. Martino R, Santamaria A, Pericas R, et al. Acute rhabdomyolysis and myonecrosis complicating Aeromonas bacteremia in neutropenic patients with hematologic malignancies: report of two cases. Haematologica January 1997;82:692-694. 